\title{
Parâmetros Tecnológicos, Comerciais e Nutracêuticos do Açaí (Euterpe 0leracea)
}

\author{
Fernanda de Paiva Badiz Furlaneto'; Anelisa de Aquino Vidal Lacerda Soares'; \\ Laura Badiz Furlaneto ${ }^{2}$ \\ $\triangle \underline{\text { fernandafurlaneto@apta.sp.gov.br }}$
}

1. Agência Paulista de Tecnologia dos Agronegócios (APTA), SP, Brasil. 2. Universidade de Marília (UNIMAR), SP, Brasil.

\section{Histórico do Artigo:}

Recebido em: 28 de novembro de 2019 Aceito em: 03 de fevereiro de 2020 Publicado em: 30 de abril de 2020

Resumo: Dada à tendência crescente do consumo do açaí-fruto objetivou-se sumariar dados referentes aos parâmetros tecnológicos, comerciais e nutracêuticos do açaí (Euterpe oleracea) explorado no Brasil. Os dados foram apresentados na forma descritiva, após a revisão integrativa da literatura. Notou-se que a exploração comercial do açaí, por ser uma atividade relativamente recente (década de 1990), precisa de ajustes tecnológicos relacionados ao sistema de produção necessitando-se de estudos referentes ao melhoramento do açaizeiro visando disponibilizar novas cultivares. Atualmente, o maior entrave na cadeia produtiva do açaí refere-se ao transporte do campo para os entrepostos e/ou indústria de processamento e a logística de distribuição do produto processado. A informalidade é fator contribuinte na contaminação dos produtos colocando em riscos à saúde do consumidor. Por ser um produto altamente perecível, mesmo sob refrigeração, torna-se primordial pesquisas direcionadas para tecnologias de processamento e conservação do açaí. Observou-se ser imprescindível intensificar a fiscalização sanitária nos locais de venda direta ao consumidor e agroindústrias de processamento levando em consideração 0 fato da polpa do açaí ser alcalina, facilitando a proliferação de fungos e bactérias, além do risco de transmissão oral da Doença de Chagas. Identificou-se pesquisas que comprovaram efeitos benéficos de alguns compostos bioativos do açaí para a saúde humana. E, em termos de uso como fármacos, vislumbra-se diversas alternativas de emprego na área da saúde a curto e médio prazo. Tal aptidão tem despertado o interesse de pesquisas na comunidade científica nacional e internacional.

Palavras-chave: Açaí-fruto, Sistema de Produção, Aspectos Mercadológicos, Cadeia Produtiva, Valor Nutricional, Efeito Terapêutico.

\section{Technological, Commercial and Nutracetic Parameters of Açaí (Euterpe Oleracea)}

Abstract: Given the growing trend of açaí-fruit consumption, the objective was to summarize data regarding the
technological, commercial and nutraceutical parameters of açaí (Euterpe oleracea) explored in Brazil. The data
were presented in a descriptive form, after the integrative literature review. It was noted that the commercial
exploitation of açaí, as it is a relatively recent activity (1990s), needs technological adjustments related to the
production system requiring studies related to the improvement of açaí in order to provide new cultivars. Currently,
the biggest obstacle in the açaí production chain refers to transport from the field to warehouses and / or the
processing industry and the logistics of distribution of the processed product. Informality is a contributing factor
in the contamination of products, putting consumers' health risks at risk. As it is a highly perishable product, even
under refrigeration, research directed towards processing technologies and açaí conservation is essential. It was
observed to be essential to intensify sanitary inspection in places of direct sale to consumers and processing agro-
industries, taking into account the fact that the açaí pulp is alkaline, facilitating the proliferation of fungi and
bacteria, in addition to the risk of oral transmission of Chagas Disease. . Research has been identified that has
proven beneficial effects of some bioactive compounds of açaí on human health. And, in terms of use as drugs,
there are several alternatives for employment in the health area in the short and medium term. Such aptitude has
aroused the interest of research in the national and international scientific community. Keywords: Açaí Fruit, Production System, Marketing Aspects, Production Chain, Nutritional Value, Therapeutic Effect. 


\section{Parámetros Tecnológicos, Comerciales y Nutrácticos de Açaí (Euterpe 0leracea)}

Resumen: Dada la tendencia creciente del consumo de açaí-fruta, el objetivo era resumir datos sobre los parámetros tecnológicos, comerciales y nutracéuticos del açaí (Euterpe oleracea) explorados en Brasil. Los datos se presentaron en forma descriptiva, después de la revisión integradora de la literatura. Se observó que la explotación comercial del açaí, como es una actividad relativamente reciente (década de 1990), necesita ajustes tecnológicos relacionados con el sistema de producción que requieren estudios relacionados con la mejora del açaí para proporcionar nuevos cultivares. Actualmente, el mayor obstáculo en la cadena de producción de açaí se refiere al transporte desde el campo hasta los almacenes y / o la industria de procesamiento y la logística de distribución del producto procesado. La informalidad es un factor que contribuye a la contaminación de los productos y pone en riesgo los riesgos para la salud de los consumidores. Debido a que es un producto altamente perecedero, incluso bajo refrigeración, la investigación dirigida a tecnologías de procesamiento y conservación de açaí es primordial. Se observó que era esencial intensificar la inspección sanitaria en los lugares de venta directa a los consumidores y las agroindustrias de procesamiento, teniendo en cuenta el hecho de que la pulpa de açaí es alcalina, lo que facilita la proliferación de hongos y bacterias, además del riesgo de transmisión oral de la enfermedad de Chagas. . Se han identificado investigaciones que han demostrado los efectos beneficiosos de algunos compuestos bioactivos de açaí en la salud humana. Y, en términos de uso como drogas, existen varias alternativas para el empleo en el área de la salud a corto y mediano plazo. Tal aptitud ha despertado el interés de la investigación en la comunidad científica nacional e internacional.

Palabras clave: Fruta Açaí, Sistema de Producción, Aspectos de Comercialización, Cadena de Producción, Valor Nutricional, Efecto Terapéutico.

\section{INTRODUÇ̃̃o}

As principais palmeiras brasileiras com relevância social e econômica pertencem ao gênero Euterpe. As espécies Euterpe oleracea Martius (conhecido como “açaí de várzea”), Euterpe precatoria Martius (“açaí de terra firme”) e Euterpe edulis Martius (“açaí da Mata Atlântica”) são as mais exploradas comercialmente (COUT0, 2013).

A E. precatória e E. edulis são destinadas, primordialmente, a produção de palmito. Entre elas, a espécie mais apreciada é a E. edulis, conhecida como palmiteiro juçara ou içara (OLIVEIRA et al., 2012).

Já, no caso do açaizeiro, palmeira da espécie E. oleracea, os dois principais produtos são o palmito e o fruto. Populações naturais dessa espécie de açaí são encontradas em solos de igapó e terra firme, porém com maior frequência e densidade em solos de várzea.

No Brasil, na região do estuário do rio Amazonas (Pará), o açaizeiro (E. oleracea) destacase por ser a palmeira mais produtiva. Grandes áreas são cobertas quase que exclusivamente por açaizeiros maciços. 0 fruto, matéria-prima para a obtenção do "suco de açai", bebida símbolo do estado do Pará, é o principal produto oriundo da palmeira (SANTOS et al., 2012). 
0 Brasil é o maior produtor, consumidor e exportador do açaí-fruto. Atualmente, a expansão econômica, atinge mercados no sudeste do país e alguns países da Europa, Estados Unidos, Japão e China. No Brasil a safra de açaí, ano 2018, foi estimada em 1,3 milhões de toneladas, em uma área aproximada de 252 mil hectares (IBGE, 2019).

0 açaí, considerado um alimento nutracêutico, tornou-se cada vez mais objeto de estudos, fator esse atribuído principalmente à sua ação antioxidante (LOBO; VELASQUE, 2016).

Dada à importância ambiental, social e econômica da cadeia produtiva do açaí-fruto objetivou-se sintetizar dados referentes ao sistema produtivo, mercadológico, nutricional e terapêutico do açaizeiro (E. oleracea) explorado no Brasil.

\section{MATERIAL E MÉTODOS}

Utilizou-se como método para coleta dos dados à revisão integrativa da literatura (BOTELHO et al., 2011). 0 levantamento bibliográfico envolveu publicações científicas nacionais e internacionais. 0s resultados foram apresentados na forma descritiva direcionados à realidade brasileira.

A revisão de literatura ocorreu no período de agosto de 2019 a outubro de 2019. Foram consultadas as seguintes bases de dados para levantamento dos artigos científicos: Lilacs, Pubmed, Scielo, Scielo BR, Scopus, Web of science e Willey.

As palavras-chaves utilizadas no processo de busca dos trabalhos corresponderam aos termos principais "açaí" e "Euterpe" utilizando o booleano (0R) entre eles, além dos descritores

relacionados à "produção”, “comercialização”, “análise física e química”, “compostos bioativos” e "efeito terapêutico", inserindo o operador booleano (AND) entre os descritores, com data limite de busca até o dia 31 de outubro de 2019.

Do total de citações obtidas, foram selecionados 32 artigos para a elaboração do texto. Nas publicações escolhidas os descritores encontravam-se nas seções de título e/ou resumo.

\section{RESULTADOS E DISCUSSÃ0}

Caracterização botânica, distribuição geográfica e produção 
Comumente, ocorrem dúvidas em relação à diferenciação botânica entre a palmeira $E$. oleracea (açaí-fruto) e E. edulis (palmito-juçara). Todavia, a E. oleracea (açaí-fruto) apresenta abundância de perfilhos em sua base (touceiras com cerca de 13 plantas); estipe delgado, sem espinho e de cor clara. Alcança 15 a $20 \mathrm{~m}$ de altura e 12 a $18 \mathrm{~cm}$ de diâmetro. Sustenta um capitel de 12 a 14 folhas pinadas, com longas bainhas superpostas, formando uma região colunar de cor verde-oliva, no extremo do estipe (Figura 1).

Produz frutos em forma de drupas, obliquamente globosos, com diâmetro de 1 a 2 cm e peso médio de 1,5 g. Estima-se um rendimento médio de polpa de 7\% em relação ao peso do fruto. Aproximadamente, $70 \%$ do peso do cacho correspondem aos frutos. A cor do fruto maduro varia entre roxa a quase preta (OLIVEIRA et al., 2012).

Já, a E. edulis (palmito-juçara) caracteriza-se por possuir uma única estipe (caule) e não rebrota após o corte. Pode alcançar até $18 \mathrm{~m}$ de altura e um diâmetro de $15 \mathrm{~cm}$ na idade adulta. Entre o término do tronco e a parte onde nascem as folhas, há uma bainha verde tubular formada pela base do conjunto de folhas. Dentro dela, encontra-se o palmito, que possui elevada importância na alimentação humana. É nativo da Mata Atlântica, tendo distribuição preferencial ao longo do litoral brasileiro.
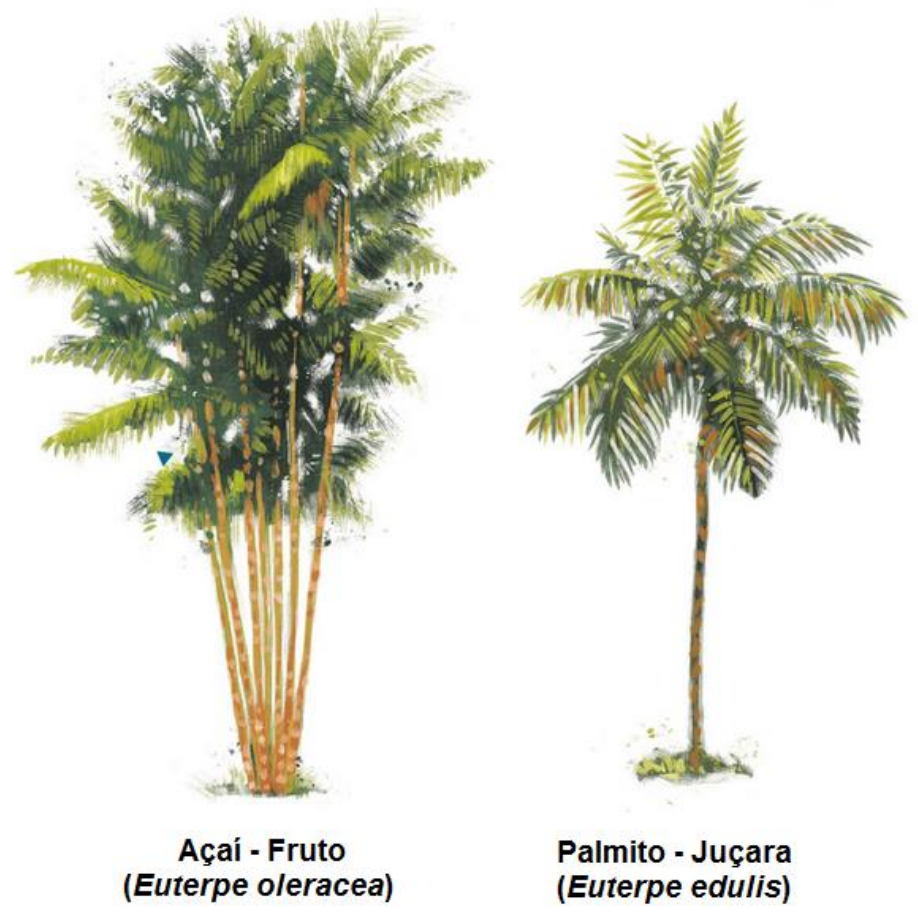

Figura 1. Características botânicas das palmeiras E. oleracea e E. edulis. Fonte: Adaptado de Wadt et al., 2004.

De acordo com o Levantamento Sistemático da Produção Agrícola (LSPA, 2019), o estado do Pará responde por, aproximadamente, 92\% da produção nacional, com um volume anual de 
1,2 milhões de toneladas de frutos e área plantada superior a 188 mil hectares (açaí de terra firme + açaí manejado em várzeas).

0 Pará possui quase 50 empresas que comercializam o fruto para outros estados. Introduz na economia paraense, aproximadamente, US\$1,5 bilhão. Esse valor é equivalente a 3\% do Produto Interno Bruto (PIB) do estado.

0 Amazonas é o segundo maior produtor nacional. Além de abastecer o mercado local, a produção do açaí do interior do Amazonas é exportada para quase todos os estados brasileiros e para países da Europa como França e Suíça. 0 Amazonas produziu 69 mil toneladas de frutos de açaí em 2018, o que representa uma queda de 16\% comparada à produção do ano de 2017 que registrou 81,8 mil. Apesar da quebra na produção, o alto consumo tem impulsionado empresários a investir no setor visando atender a demanda nacional e internacional.

Os demais estados do Norte apesar de figurar entre os produtores nacionais não tem expressão representativa no contexto da produção do país se comparados aos estados do Pará e o Amazonas, entretanto, pode-se identificar grande potencialidade de produção no futuro (IBGE, 2019).

A palmeira nativa E. oleracea (açaí-fruto) inicia a floração a partir do $4^{\circ}$ ano de plantio. Quando bem manejada, pode iniciar a floração por volta de 2,5 anos do plantio, podendo o primeiro cacho ser colhido entre 3,1 e 3,5 anos. As plantas nativas apresentam idade de reprodução entre 5 e 20 anos e vida útil média de 20 anos.

A partir do $3^{0}$ ano após o plantio as touceiras cujos estipes adultos foram retirados iniciarão a frutificação no ano seguinte. Depois que inicia seu ciclo reprodutivo, floresce e frutifica quase 0 ano todo, mas, os períodos de maior floração e frutificação concentram-se na época mais chuvosa (janeiro a maio) e menos chuvosa (setembro a dezembro), respectivamente.

A safra é mais expressiva nos meses de agosto a janeiro. A colheita do fruto pode ser feita, aproximadamente, seis meses após a antese (florescência), quando os frutos apresentam coloração violácea ou esverdeada, opaca, devido à superfície acinzentada do exocarpo (VASCONCELOS et al., 2010).

Um açaizeiro produz em torno de 1 a 4 cachos por ano. 0 peso de um cacho oscila entre 3 a 4,5 kg. Todavia, para calcular a produtividade do local do manejo, torna-se necessário fazer uma amostragem por meio da pesagem dos frutos de 15 a 20 cachos em decorrência da grande variação de produção entre as plantas. 
Atualmente, existem dois sistemas de práticas agrícolas: em áreas de várzeas (atividade exploratória ou manejada) e em terra firme (plantio em grandes áreas).

Em termos de produção, têm-se observado que em área de várzea a produtividade média do açaí está em torno de 6 t/ha/ano, com o manejo. Em área de terra firme com adubação e irrigação, nota-se uma produtividade média de 10 t/ha/ano (COUT0, 2013).

Nas áreas de várzeas, açaizais nativos manejados estão concentrados no estuário dos rios Tocantins, Pará e Amazonas. No Pará, o período de safra do açaí ocorre entre julho a dezembro (representa 70 a 80\% da produção do açaí). A produção da safra do estuário amazônico concentra-se no verão, sendo duas a três vezes superior à da safra de inverno. A produção do açaí irrigado concentra-se nos meses de novembro (30\%), dezembro (30\%), janeiro (25\%), fevereiro, março e abril (5\%).

Notou-se que o primeiro cacho se apresenta bastante cheio, seguido de outro menor e o terceiro, com produção bem inferior. Com a retirada do primeiro ao quarto cacho a planta ganha nova conformação e tende a encher novamente. Todavia, Viera et al. (2018) ressalta que para conservar o açaizal produtivo é preciso fazer manutenção a cada dois anos, por meio de roçagem e retirada das palmeiras finas e com mais de 12 metros.

\section{Sistemas de plantio, processamento e classificação}

A ocupação em terra firme tornou-se viável em decorrência do programa de melhoramento do açaí, desenvolvido pela EMBRAPA, que resultou no lançamento do cultivar “BRS Pará”, no ano 2005. Essa variedade apresenta produção de frutos precoce, com a primeira frutificação aos três anos após o plantio, produtividade média estimada em torno de 10 t/ha/ano, a partir do $8^{\circ}$ ano de plantio e rendimento de polpa variando de 15 a $25 \%$.

Os espaçamentos indicados para o cultivo do açaizeiro solteiro (monocultivo) encontram-se em testes, sendo os mais utilizados: $5 \mathrm{~m}$ x $5 \mathrm{~m}$ e $6 \mathrm{~m} \mathrm{x} 4 \mathrm{~m}$. Outros espaçamentos, também, são usados como demonstra a tabela 1.0 espaçamento de 5 m x 5 m com manejo de 3 a 4 estipes/planta, por fornecer densidades de 1.200 plantas/ha e 1.600 plantas/ha, respectivamente é o mais indicado. Esse espaçamento facilita a colheita, por até 10 anos após 0 plantio, como também propicia bom desenvolvimento no diâmetro dos estipes e reduz a altura das plantas, minimizando os riscos de tombamento pela ação dos ventos (CARVALHO et al., 2005). 
Tabela 1. Espaçamentos, número de plantas, número de estipes manejados e totais de estipes de açaizeiro em cultivo solteiro (monocultivo), por hectare.

\begin{tabular}{cccc}
\hline Espaçamento $(\mathrm{m})$ & Plantas/ha & Estirpes/touceira & Estirpes/ha \\
\hline $5 \times 4$ & 500 & 3 & 1.500 \\
$5 \times 4$ & 500 & 4 & 2.000 \\
$6 \times 4$ & 416 & 3 & 1.248 \\
$6 \times 4$ & 416 & 4 & 1.664 \\
$5 \times 5$ & 400 & 3 & 1.200 \\
$5 \times 5$ & 400 & 4 & 1.600 \\
\hline
\end{tabular}

Fonte: Carvalho et al., 2005.

A colheita dos cachos inclui a debulha dos frutos e o seu transporte até o local do embarque, efetuado nas costas ou em pequenas embarcações. Escaladores são capazes de passar de um estipe para outro de uma mesma touceira, sem descer ao solo, colhendo de 3 a 5 cachos em uma única escalada, desde que o peso total não ultrapasse $15 \mathrm{~kg}$. Normalmente, um escalador experiente é capaz de coletar cerca de $150 \mathrm{~kg}$ a $200 \mathrm{~kg}$ de frutos, que equivale a, aproximadamente, a 50 a 60 cachos, em uma jornada de 6 horas de trabalho (H0MMA, 2006).

A colheita é efetuada utilizando peconha, uma espécie de laço feito de corda, cipós, pano ou da própria palha dos açaizeiros, que é colocada nos pés para facilitar a escalada dos estipes. Utilizam-se, também, varas com dispositivos em sua porção terminal que retiram os cachos dos açaizeiros, com perda insignificante de fruto. Existe, também, um coletor feito de vergalhão de ferro amarrado na ponta de uma vara. Outro modelo consiste em vara colhedora de frutos de açaí, confeccionada com alumínio.

Usa-se, ainda, um modelo (gancho com pressão na extremidade) para efetuar a mecanização em plantios com espaçamento de $6 \mathrm{~m}$ x $7 \mathrm{~m}$. Com esse procedimento consegue-se coletar 100 latas de frutos/dia. 0 aumento da produtividade da mão-de-obra é relevante se comparado com o processo tradicional, em que um escalador experiente, consegue colher entre 8 a 12 latas de frutos/dia.

0 açaí é comercializado em rasas. A rasa é uma medida local que consiste em duas latas de 20 litros (28,4 kg). Cada lata corresponde a 14,2 kg. A rasa é confeccionada com talos de arumã (Ischnosiphon ovatus), planta da família que pertence à araruta (Maranta arundinacea). A durabilidade dessas rasas é de uma safra. Para um açaizal com produção de 10.000 latas/safra ou 5.000 rasas/safra são necessários 300 cestos.

Segundo Homma (2006) o transporte dos frutos ocorre, principalmente, em barcos de intermediários. Em média um barco a motor consegue carregar 500 latas ou 250 rasas e 
necessita ter um estoque de 1.000 rasas para entregar aos produtores e gerar compromisso de entrega.

0 local de desembarque dos frutos de açaí é conhecido como "pedra". Funciona como uma bolsa de mercadoria onde os preços oscilam conforme a oferta dos frutos. Os frutos in natura são classificados, informalmente, conforme descrito na tabela 2.

Tabela 2. Classificação do açaí vendido no entreposto (atacadista) ou indústria de beneficiamento.

\begin{tabular}{ll}
\hline Classificação do açaí & \multicolumn{1}{c}{ Especificação } \\
\hline Açaí "surrado" & Quando os frutos foram transferidos para diversas rasas, \\
& medições e posterior embarque nas caixas de plástico. 0 fruto \\
& $\begin{array}{l}\text { fica ralado, prejudicando a qualidade e comprometendo o } \\
\text { rendimento no beneficiamento. }\end{array}$ \\
\hline Açaí "tuira" & Composto por frutos bem maduros. Fica coberto com um pó \\
& branco, geralmente colocado na parte superior da rasa para \\
& valorizar o produto. \\
\hline Açaí "paró" & Mistura de frutos maduros e verdes, de péssima qualidade. A \\
& Sua venda acontece quando há escassez do açaí no mercado. \\
\hline Açaí "moqueado" & Constituído de frutos que foram colhidos em dias anteriores. \\
& 0 transporte foi demorado. 0 fruto começa a secar. \\
\hline
\end{tabular}

Fonte: Adaptado de Couto et al. 2013.

Após a colheita, as etapas do processamento dos frutos são: separação de materiais estranhos; seleção dos frutos sadios e maduros; higienização; repouso em água morna (aproximadamente $40^{\circ} \mathrm{C}$ ) durante 30 minutos, para o amolecimento da polpa e casca; e despolpamento.

Comercializa-se a polpa de açaí na forma congelada ou temperatura ambiente/resfriada. Existem diferentes tipos de açaí e polpas. Os principais tipos de açaí encontram-se descritos na tabela 3.0 açaí roxo e açaí branco são os mais consumidos no mercado brasileiro em decorrência da palatabilidade (VASCONCELOS et al., 2010).

Tabela 3. Principais tipos de açaí comercializados no Brasil.

\begin{tabular}{ll}
\hline Tipos de açaí & Especificação \\
\hline Açaí Roxo ou Preto & Semelhante à jabuticaba, esse tipo de açaí é retirado de cachos da \\
& $\begin{array}{l}\text { palmeira popularmente conhecida como açaizeira. É proveniente } \\
\text { do Norte do Brasil, principalmente, das regióes do Belém do Pará. É } \\
\\
\text { o tipo de açaí mais popular no país. }\end{array}$ \\
\hline Açaí Branco & É conhecido como açaí Tinga. É mais difícil de ser encontrado, por \\
& isso é mais caro do que o açaí roxo ou preto. Embora seja chamado \\
\hline
\end{tabular}




\begin{tabular}{ll}
\hline & $\begin{array}{l}\text { de açaí branco, sua casca e polpa são verdes, com tonalidades } \\
\text { semelhantes ao abacate. É muito apreciado pelos paraenses. }\end{array}$ \\
\hline Açaí Açu & $\begin{array}{l}\text { Possui um sabor mais forte que o açaí roxo. Tem origem na } \\
\text { Amazônia peruana. Os cachos são maiores que do açaí roxo, por isso } \\
\text { o nome “Açu” (açaí grande). Conhecido como açaí solitário ou açaí } \\
\text { do Amazonas, é plantado na região sul de Tocantins. Proporciona a } \\
\text { "produção de inverno”, ou seja, a entressafra do açaí roxo ou preto. }\end{array}$ \\
\hline Açaí Espada & $\begin{array}{l}\text { Recebe esse nome devido ao seu formato diferente. Seus cachos } \\
\text { apresentam uma série de ramificações, tornando-o um fruto único. }\end{array}$ \\
\hline Açaí Sangue de Boi & $\begin{array}{l}\text { Recebe esse nome, pois, quando maduro, exibe uma coloração } \\
\text { vermelha muito intensa. Não tem boa aceitação, por possui }\end{array}$ \\
& $\begin{array}{l}\text { consistência pastosa e sabor desagradável quanto comparado ao } \\
\text { açaí roxo. }\end{array}$ \\
\hline Açaí Chumbinho & $\begin{array}{l}\text { Trata-se de uma variedade extremamente pequena. Cada fruto } \\
\text { dessa espécie pesa cerca de lg. Sua coloração varia entre o roxo e o } \\
\text { branco. }\end{array}$ \\
\hline Fonte: Adaptado de Vasconcelos et al., 2010.
\end{tabular}

De acordo com Couto et al. (2013), o uso de despolpadeiras pode ser classificado em tradicional (semi-industrial) e industrial. 0 primeiro, típico para pequena escala, é realizado em máquinas verticais, compostas por um cilindro de aço inoxidável largo na parte superior e afunilado na inferior. 0s frutos são despejados na parte superior do cilindro e batidos com adição progressiva de água. Uma emulsão se forma e o açaí desce por gravidade passando por uma peneira para então ser coletado na saída do funil.

0 despolpamento industrial conta com despolpadeiras horizontais, compostas por um cilindro de aço inoxidável na posição horizontal e sistema de saída para circuito fechado. Os modelos verticais existentes atualmente no mercado têm capacidade de processar 24 a $48 \mathrm{~kg}$ de fruto/hora. Já as máquinas horizontais têm capacidade de 300 a $6.000 \mathrm{~kg} / \mathrm{hora}$.

Em processos industriais o açaí que sai da despolpadeira entra imediatamente em um circuito fechado até ser envasado. Como recorrente em indústrias de processamento de frutas, o açaí é conduzido a um homogeneizador e, em seguida, ao pasteurizador.

Após a pasteurização é envasado e imediatamente congelado em túneis de congelamento ou em câmara fria. 0 tratamento e congelamento imediato visam reduzir as perdas nutricionais em função da atividade de enzimas e de microrganismos. Além de atender os quesitos sanitários exigidos aos produtos alimentares (COUT0, 2013).

Visando a padronização do produto foi instituída a Instrução Normativa $\mathrm{n}^{\circ} 1$ de 07/01/2000 do Ministério da Agricultura, Pecuária e Abastecimento para fixação do Padrão de Identidade e Qualidade (PIQ) para o açaí (BRASIL, 2000). 
A referida instrução fixa algumas características físicas e químicas, a saber: pH: 4,00 6,20; acidez total expressa em ácido cítrico (g/100 g): 0,27 (fino) - 0,40 (médio) - 0,45 (grosso); lipídios totais: 20,0 - 60,0 g/100 g de matéria seca; proteínas: mín. 6,0 g/100 g de matéria seca; açúcares totais: máx. 40,0 g/100 g de matéria seca. Características sensoriais: aspectos físicos: a emulsão deve ficar estável mesmo se for aquecida a $80{ }^{\circ} \mathrm{C}$; cor: roxo violáceo; sabor: não adocicado e não azedo; cheiro: característico.

Os parâmetros microbiológicos correspondem ao padrão estabelecido para polpas de frutas em geral, como segue abaixo: soma de bolores e leveduras: máximo 5 x $10^{3} \mathrm{UFC} / \mathrm{g}$ para polpa "in natura", congelada ou não, e 2 x $103 \mathrm{UFC/g}$ para polpa conservada quimicamente e/ou que sofreu tratamento térmico; coliformes termotolerantes: $<1 / \mathrm{g}$; Salmonella sp:: ausente em $25 \mathrm{~g}$.

Em relação à comercialização da polpa do açaí existem basicamente três tipos de classificação, sendo elas: polpa grossa ou especial, polpa média ou regular e polpa fina ou popular. Os tipos de polpas correspondem à quantidade de sólidos totais e porcentagem de adição de água, conforme define a Portaria $n^{0} 78$ do Ministério Amazônia da Agricultura e Abastecimento, de 17 de março de 1998 (BRASIL, 1998), a saber:

a) polpa de açaí grossa ou especial (tipo A): polpa extraída com adição de água e filtração, apresentando acima de 14\% de sólidos totais. Teor de água inferior a 86\%. É pouca utilizada, pois contém grande quantidade de sólidos em sua composição, apresentando um sabor mais forte (“terroso”); b) polpa de açaí média ou regular (tipo B): polpa extraída com adição de água e filtração, apresentando entre 11 a 14\% de sólidos totais. Teor de água entre $86 \%$ e 89\%. É conhecida como creme de açaí e considerada a melhor para consumo. Apresenta o sabor mais autêntico do açaí; c) polpa de açaí fina ou popular (tipo C): polpa extraída com adição de água e filtração, apresentando entre $8 \%$ e 11\% de sólidos totais. Teor de água entre $89 \%$ e 92\%. É a mais utilizada devido ao seu baixo custo.

\section{Aspectos mercadológicos e custo de implantação}

Do total do açaí comercializado, aproximadamente, 83\% provém do açaizeiro cultivado (plantado e/ou manejado) e 17\% do extrativismo. Cerca de 60\% da produção é consumida pelos paraenses, 30\% é comercializada para outros estados e 10\% para o mercado internacional, principalmente para os Estados Unidos. Enfatiza-se, também, que o cultivo do açaí é a atividade mais representativa da fruticultura paraense e insere no mercado mais de 25 mil pessoas, de 
forma direta e indireta. Responde por, aproximadamente, $70 \%$ da formação da renda dos extrativistas ribeirinhos.

Insta frisar que o consumo nacional de açaí extra-amazônico aumentou significativamente a partir dos anos 1990 quando a classe média a alta da região sul e sudeste do Brasil iniciou o consumo do fruto como um alimento, principalmente, entre praticantes de esportes, pelo seu caráter energético e antioxidante (IBGE, 2019).

No tocante às variações dos preços do açaí nota-se, em sua maioria, que são determinadas por períodos de safra e entressafra (NOGUEIRA; SANTANA, 2009). Destaca-se, ainda, que anualmente, o Ministro de Estado da Agricultura, Pecuária e Abastecimento publica o preço mínimo de produtos extrativos a ser pago aos produtores. 0 valor mínimo para o ano de 2017, 20182019 correspondeu, respectivamente, a R\$ 1,29, R\$ 1,60 e R\$ 1,63 / kg de açaí (CONAB, 2019).

Na tabela 4 encontra-se descrita a variação do preço pago ao produtor nos meses de julho/18, junho/19 e julho/19. Em julho de 2019, a média do preço da rasa foi de $\mathrm{R} \$$ 60,50. Desse valor, $20 \%$ paga-se ao peconheiro (extrativista que sobe nas palmeiras para colher o fruto).

Tabela 4. Preço pago ao produtor de açaí $(\mathrm{R} \$ / \mathrm{kg})$, variação em relação ao mês anterior $(\%)$ e variação do preço em relação ao ano anterior (\%)

\begin{tabular}{lccccc}
\hline UF & Julho/18 & Junho/29 & Julho/19 & $\begin{array}{c}\text { Variação (\%) } \\
\text { (mês anterior) }\end{array}$ & $\begin{array}{r}\text { Variação (\%) } \\
\text { (ano anterior) }\end{array}$ \\
\hline Pará & 2,55 & 4,32 & 3,83 & $-11,34$ & 50,20 \\
Amazonas & 1,91 & 1,20 & 1,24 & 3,30 & $-35,10$ \\
Maranhão & 2,83 & 3,57 & 3,00 & $-15,97$ & 6,00 \\
Amapá & 0,94 & 1,68 & 1,56 & $-7,14$ & 65,90 \\
Rondônia & 2,00 & 2,10 & 1,90 & $-9,50$ & $-5,00$ \\
Acre & 1,25 & 1,27 & 1,25 & $-1,50$ & 0,00 \\
Fonte: CONAB, 2019. & & & & &
\end{tabular}

0 Amazonas é o estado que tem apresentado maior desvalorização do preço pago ao produtor no último ano. 0 estado tem sofrido com o período de estiagem o que tem impactado nos custos gerais de produção devido à dificuldade de escoamento do produto na região.

0 preço do açaí comercializado no Pará aumentou quase 30\% desde o início do ano, registrando alta em todos os meses do ano até junho, se comparado ao mesmo período do ano anterior o aumento foi de 50\% aproximadamente. Contudo de junho a julho houve pela primeira vez no ano, diminuição no preço pago ao produtor. Tendência observada nos últimos anos no 
mesmo período devido, provavelmente, a estabilização da demanda/oferta durante o período de safra (IBGE, 2019).

Em relação ao custo de implantação de um hectare de açaí irrigado, Nascimento et al. (2016) estimaram um investimento em torno de $\mathrm{R} \$ 7.00,00$ a $\mathrm{R} \$ 11.000,00$ por hectare. A irrigação, normalmente, se inicia a partir do $2^{\circ}$ ano de safra. Calcula-se a demanda de 100 a 120 litros de água por dia por touceira. Todavia, novos estudos são necessários para estabelecer a variação desses custos dependendo de cada localidade e condições edafoclimáticas.

Insta frisar que o custo de médio das operações envolvidas na produção do açaí deve envolver o custo de implantação (ano 0), tratos culturais e manutenção (anos 1 a 19), colheita e transporte (anos 4 a 20), administração (anos 0 a 20), produtividade (anos 4 a 20, considerando que a partir do ano 10, passa-se a inserir quedas de produtividade na ordem de 5\%) e vida útil da cultura de 20 anos (SANTOS et al., 2008; NOGUEIRA et al., 2013).

Destaca-se que um dos maiores entraves que a cadeia de açaí tem enfrentado nos estados cuja produção é menor, é o custo com o transporte que, normalmente, supera o custo da matéria prima, tornando o processo de produção muito oneroso. Diante desse cenário, o desenvolvimento de novas cultivares visando otimizar a produção, bem como a instalação de novas indústrias de processamento da polpa de açaí podem incrementar o mercado do açaí nessas localidades (SOUZA et al., 2012).

\section{Parâmetros nutricionais e terapêuticos}

Quanto ao valor nutricional, o açaí destaca-se pelo teor lipídico e o teor de compostos fenólicos, além de apresentar relevantes teores de proteínas, fibras alimentares e macro e micronutrientes (ROGEZ, 2000).

É um alimento pouco ácido e de baixo valor glicêmico, com teores de açúcares assimiláveis (glicose, frutose e sacarose) entre $2 \%$ a $3 \%$ da matéria seca. 0s principais constituintes da matéria seca são lipídeos $(50 \%)$, fibras alimentares $(25 \%)$ e proteínas $(10 \%)$, em valores médios (NASCIMENT0 et al., 2008).

Não somente o valor de lipídeos totais, mas o perfil de ácidos graxos é igualmente atrativo. A fração lipídica do açaí é composta por 74\% de ácidos graxos insaturados, dentre eles, ácido oleico (56\%), ácido linoleico (11\%) e linolênico (0,8\%). Dentre os ácidos graxos saturados os mais relevantes correspondem ao ácido palmítico (24\%) e o ácido esteárico (2\%), totalizando cerca de 26\% de ácidos graxos saturados (SCHIRMANN, 2009). 
Os pigmentos naturais do açaí, tais como antocianinas e carotenoides, têm grande aplicação como corante natural na indústria alimentícia. Santos (2018) trabalhando com $E$. oleracea e E. edulis identificou a cianidina-3-glucosídeo e cianidina-3-rutinosídeo como as principais antocianinas de ambas as espécies.

Heinrich et al. (2011) destacou, também, que a composição química do açaí pode trazer grandes benefícios na prevenção da aterosclerose por conter elevada quantidade de vitamina E, sendo, portanto, um antioxidante natural, importante na eliminação dos radicais livres. A quantidade de fibras favorece o trânsito intestinal. A vitamina Bl e o teor de pigmentos antocianinas auxiliam na circulação do sangue. 0 seu consumo está associado à prevenção de doenças cardiovasculares. Os autores enfatizaram, ainda, que entre os antioxidantes predominantemente presentes na polpa do fruto, encontram-se os flavonoides, as antocianinas e os compostos fenólicos.

Os flavonoides são compostos bioativos do grupo dos polifenóis. Possuem propriedades anti-inflamatória, hormonal, anti-hemorrágica e antialérgica. São responsáveis pelo aumento da resistência capilar e otimização da absorção da vitamina C. Também são conhecidos por fator P (de permeabilidade) ou substância P. Todavia, o efeito mais importante dos flavonoides é a propriedade antioxidante.

Os antioxidantes são capazes de interceptar os radicais livres gerados pelo metabolismo celular ou por fontes exógenas, impedindo o ataque sobre os lipídeos, aminoácidos das proteínas, ácidos graxos poliinsaturados e bases do DNA, evitando a formação de lesões e perda da integridade celular. Reduzem a senescência celular. Na farmacologia é estudado de forma intensiva, sobretudo em tratamentos de problemas cardiovasculares e doenças neurodegenerativas visando combater o estresse oxidativo (CEDRIM et al., 2018).

Já, as antocianinas são pigmentos pertencentes ao grupo dos flavonoides responsáveis pela variedade de cores de frutas, flores e folhas. Em particular, são os responsáveis pela cor rubi-violácea (cor "bordô"). De acordo com Santos et al. (2014) alimentos ricos em antocianinas reduzem níveis de LDL-c e aumentam níveis de HDL-c. 0 potencial antioxidante dessa substância previne o aparecimento de aterosclerose e doenças cardiovasculares.

Os compostos fenólicos relacionam-se a um grupo de antioxidantes não enzimáticos que combatem os radicais livres. Apresentam bioatividade ligada à sua capacidade de quelatar metais, inibir a enzima lipoxigenase e sequestrar radicais livres. Pesquisas indicam que os compostos fenólicos possuem capacidade antioxidante, com elevado potencial farmacológico com destaque para a atividade antiulcerogênica (MEL0 NET0, 2018). 
Santos (2018) ressaltou, ainda, que o efeito mais importante do açaí na função vascular é a vasodilatação que ocorre devido à ação das antocianinas. Apesar do consumo da fruta não melhorar diretamente a pressão arterial em indivíduos normotensos, a ingestão de $150 \mathrm{~g}$ de polpa de açaí em um teste agudo causou um aumento de 1,4\% na dilatação mediada por fluxo da artéria braquial nos participantes do estudo, representando uma melhora significativa na função vascular. Outro benefício apresentado pelo consumo da fruta foi à redução dos índices de colesterol total e triglicérides e o aumento dos níveis de HDL.

Todavia, pesquisadores alertam que o açaí é um produto altamente perecível, alterando rapidamente suas características físicas, químicas e sensoriais dentro de 72 horas, mesmo sob refrigeração. Além da oxidação das antocianinas e dos lipídeos, a elevada carga microbiana tem expressiva participação na rápida degradação e perda de qualidade do açaí (ALEXANDRE et al., 2004).

Nessa acepção, para minimizar o problema, o Centro de Pesquisa Agropecuária da EMBRAPA, em Belém, desenvolveu uma tecnologia para a obtenção do açaí desidratado. Outro método que está sendo utilizado pelas indústrias de sorvetes da região é submeter o suco "concentrado" à temperatura de $40{ }^{\circ} \mathrm{C}$ preservando grande parte de suas propriedades (BARBOSA et al., 2017).

Outro aspecto importante a ser considerado pelas autoridades sanitárias e órgãos fiscalizadores é o fato de o açaí ser uma das possíveis causas de contaminação por via oral da Doença de Chagas Aguda (DCA).

Entre 2007 e 2016, o Brasil registrou, em média, 200 casos agudos de DC por ano. Destes casos, $69 \%$ foram causados por transmissão oral, derivada da contaminação de bebidas e comidas. Embora casos de infecção já tenham sido ligados ao consumo de outros alimentos (como caldo de cana), o açaí é o item mais frequentemente associado a essa rota de transmissão do Trypanosoma cruzi.

Entre as notificações registradas, cerca de 95\% ocorreram na região Norte, com 85\% no estado do Pará, onde o consumo do suco fresco de açaí é um item tradicional da cultura alimentar. Em relação às principais formas prováveis de transmissão relatadas atualmente no país, $72 \%$ aconteceram por transmissão oral, $9 \%$ por transmissão vetorial e $18 \%$ não foram identificadas (SUSAM, 2019).

Convém salientar que em termos de medicamentos e fármacos avista-se inúmeras possibilidades em curto prazo. Pode-se citar o processo de patenteamento iniciado pela Embrapa Amazônia Oriental e pela Universidade Federal do Pará (UFPA) do uso do corante de 
açaí como identificador de placa bacteriana. Entretanto, a burocratização do processo de registro de patentes no Brasil coloca em risco as tecnologias/produtos gerados pela pesquisa científica no país tendo em vista à concorrência internacional (SANTANA et al., 2014).

\section{CONCLUSÃ0}

A exploração comercial do açaí, por ser uma atividade relativamente recente, datada da década de 1990, precisa de ajustes tecnológicos relacionados ao sistema de produção como espaçamento de plantio, manejo nutricional e hídrico, bem como condução da lavoura

Há necessidade de intensificação de estudos de melhoramento do açaizeiro visando disponibilizar novas opções de cultivares. Salienta-se que a variedade "BRS Pará" impulsionou a expansão do plantio de açaizeiros para fins comerciais (principalmente direcionado para agroindústrias de polpa congelada).

Atualmente, o maior entrave na cadeira produtiva do açaí refere-se ao transporte do campo para os entrepostos e/ou indústria de processamento e a logística de distribuição do produto processado. Além disso, a informalidade é fator contribuinte na contaminação dos produtos acarretando riscos à saúde do consumidor.

Por ser um produto altamente perecível, alterando rapidamente suas características físicas, químicas e sensoriais, mesmo sob refrigeração, torna-se primordial pesquisas direcionadas para tecnologias de processamento e conservação do açaí.

Observou-se ser imprescindível intensificar a fiscalização sanitária nos locais de venda direta ao consumidor e agroindústrias de processamento do açaí levando em consideração o fato da polpa do açaí ser alcalina, facilitando a proliferação de fungos e bactérias, além do risco de transmissão oral da Doença de Chagas.

Por ser um produto nutracêutico, o campo de investigação científica é amplo. Pesquisas recentes já comprovaram os efeitos na saúde humana de alguns compostos bioativos presentes no açaí.

Em termos de uso como fármacos vislumbra-se diversas alternativas de emprego na área da saúde a curto e médio prazo. Tal aptidão tem despertado o interesse de pesquisas na comunidade científica nacional e internacional. 


\section{REFERÊNCIAS BIBLIOGRÁFICAS}

ALEXANDRE, D.; CUNHA, R. L., HUBINGER, M. D. Conservação do açaí pela tecnologia de obstáculos. Ciência e Tecnologia de Alimentos, Campinas, v. 24, n. 1, p.114-119, 2004.

BARBOSA, E. C.; BUENO, M. P. N.; SILVA, S. C. R.; MALTA, L. G. Avaliação sensorial do açaí liofilizado em pó, açaí em pó e polpa do açaí. Revista Brasileira de Produtos Agroindustriais, Campina Grande, v. 19, n. 4, p. 375-379, 2017.

BOTELHO, L. L. R.; CUNHA, C. C. A.; MACEDO, M. 0 método da revisão integrativa nos estudos organizacionais. Gestão e sociedade, Belo Horizonte, v. 5, n. 11, p. 121-136, 2011.

BRASIL. Ministério da Agricultura, Pecuária e Abastecimento. Instrução Normativa nº 01, de 07 de janeiro de 2000. Aprova padrões de identidade e qualidade para polpas de frutas. Brasília: MAPA, 2000.

BRASIL. Ministério da Agricultura, Pecuária e Abastecimento. Portaria no 78, de 17 de março de 1998. Normas de qualidade bromatológica para o açaí. Brasília: MAPA, 1998.

CARVALHO, J. E. U.; OLIVEIRA, M. S. P.; FARIAS NETO, J. T.; NASCIMENTO, W. M. 0. Açaí: espaçamentos indicados e consórcios. Brasília: Agência Embrapa de Informação Tecnológica (AGEITEC), p. 1-3, 2005.

CEDRIM, P. C. A. S.; BARROS, E. M. A.; NASCIMENTO, T. G. Propriedades antioxidantes do açaí (Euterpe oleracea) na síndrome metabólica. Brazilian Journal of Food Technology, Campinas, v.21, p. 1-7, 2018.

CONAB. Companhia Nacional de Abastecimento. Conjuntura mensal fruto do açaí. 2019. Disponível em: https://www.conab.gov.br/acesso-a-informacao. Acesso em 08 out. 2019.

COUT0, M. C. M. Beneficiamento e comercialização dos produtos dos sistemas agroflorestais na Amazônia. 2013. 138 f. Dissertação (Mestrado em Agricultura Familiar e Desenvolvimento Sustentável)- Universidade Federal do Pará, Belém.

HEINRICH, M.; DHANJI, T.; CASSELMAN, I. Açai (Euterpe oleracea Mart.): a phytochemical and pharmacological assessment of the species health claims. Phytochemistry Letters, Amsterdã, v. 4, n. 1, p. 10-21, 2011.

HOMMA, A. K. 0.; NOGUEIRA, 0. L.; MENEZES, A. J. E. A.; CARVALHO, J. E. U.; NICOLI, C. M. L.; MATOS, G. B. Açaí: novos desafios e tendências. Amazônia Ciência e Desenvolvimento, Belém, v. 1, n. 2, p.7-23, 2006.

IBGE. Instituto Brasileiro de Geografia e Estatística. Produção da extração vegetal e da silvicultura. Rio de Janeiro: IBGE, 2019. Disponível em: https://www.ibge.gov.br/producao-da-extracao-vegetal-e-da-silvicultura. Acesso em 11 out. 2019.

LOB0, A. C. M.; VELASQUE, L. F. L. Revisão de literatura sobre os efeitos terapêuticos do açaí e sua importância na alimentação. Biosaúde, Londrina, v. 18, n. 2, p. 97-106, 2016.

LSP. Levantamento Sistemático da Produção Agrícola. Açaí: área plantada, área colhida, quantidade produzida e rendimento médio de produtos. Rio de Janeiro: IBGE, 2018. Disponível em: https://www.ibge.gov.br/estatisticas/levantamento-sistematico-da-producao-agricola. Acesso em 18 out. 2019.

MELO NET0, Domingos Ferreira. Análise proteômica de sementes em desenvolvimento de açaí (Euterpe oleracea Mart). 2018. 114 f. Dissertação (Mestrado em Agronomia Fitotecnia)- Universidade Federal do Ceará, Fortaleza.

NASCIMENTO, R. J. S.; COURI, S.; ANTONIASSI, R.; FREITAS, S. P. Composição em ácidos graxos do óleo da polpa de açaí extraído com enzimas e com hexano. Revista Brasileira de Fruticultura, Jaboticabal, v. 30, n. 2, p. 498-502, 2008.

NASCIMENTO, W. M. 0.; OLIVEIRA, M. S. P.; CARVALHO, J. E. U.; FARIAS NETO, J. T. Coeficientes técnicos, custos e rentabilidade. Brasília: Agência Embrapa de Informação Tecnológica (AGEITEC), p. 1-2, 2016.

NOGUEIRA, A. K. M.; SANTANA, A. C. Análise de sazonalidade de preços de varejo de açaí, cupuaçu e bacaba no estado do Pará. Revista de Estudos Sociais, Cuiabá, n. 11, p. 7-22. 2009. 
NOGUEIRA, A. K. M., SANTANA, A. C. e GARCIA, W. S. The dynamics of açai market in Pará State from 1994 to 2009. Revista Ceres, Viçosa, v. 60, n. 3, p. 324-331, 2013.

OLIVEIRA, M. S. P.; MOCHIUTTI, S.; FARIAS NETO, J. T. Domestication and breeding of assai palm. In: BORÉM, A; LOPES, M. T. G; CLEMENT, C. R; NODA, H. (Org.). Domestication and breeding: amazonian species. 1 ed. Viçosa: Suprema Editora, p. 209-236, 2012.

R0GEZ, H. Açaí: preparo, composição e melhoramento da conservação. Belém: Editora Universidade Federal do Pará/ EDUPA, 2000. 360 p.

SANTANA, M. F. S.; LIMA, A. K. V. 0.; MOURÃO, M. Avaliação prospectiva do açaí: análise através dos pedidos de patentes e referências. Revista Gestão, Inovação e Tecnologias, São Cristóvão, v. 4, n. 1, p. 437-452, 2014.

SANTOS, J. C.; SENA, A. L. S.; HOMMA, A. K. O. Açaí: custo do sistema de irrigação por microaspersão. Brasília: Agência Embrapa de Informação Tecnológica (AGEITEC), 2008, 2p.

SANTOS, J. C.; SENA, A. L. S.; HOMMA, A. K. 0. Viabilidade econômica do manejo de açaizais no estuário amazônico do Pará. In: GUIDUCCI, R. C. N.; LIMA FILHO, J. R.; MOTA, M. M. (Ed.). Viabilidade econômica de sistemas de produção agropecuários. Brasília: Embrapa, p. 351-409, 2012.

SANTOS, A. C. A.; MARQUES, M. M. P.; SOARES, A. K. 0.; FARIAS, L. M.; FERREIRA, A. K. A.; CARVALH0, M. L. Potential antioxidant anthocyanins in food sources: systematic review. Revista Interdiciplinar, Teresina, v. 7, n. 3, p. 149-156, 2014.

SANTOS, H. 0. Effect of açaí (Euterpe Oleracea) intake on vascular function and lipid profile: What is the recommendation? International Journal of Cardiovascular Sciences, Rio de Janeiro, v. 32, n. 2, p. 190-192, 2018.

SCHIRMANN, G. S. Composição em ácidos graxos do açaí (Euterpe edulis) de diversas regiões de Santa Catarina. 2009. 91 f. Dissertação (Mestrado em Agroecossistemas)-Universidade Federal de Santa Catarina, Florianópolis.

SOUZA, A. G. C.; SOUSA, N. R.; LOPES, R.; ATROCH, A. L.; BARCELOS, E.; CORDEIRO, E.; OLIVEIRA, M. S. P.; ALVES, R. M.; FARIAS NETO, J. T.; NODA, H. ; SILVA FILHO, D. F.; YUYAMA, K.; ALMEIDA, C. M. V. C.; LOPES, M. T. G.; OHASHI, S. T. Contribution of the institutions in the Northern region of Brazil to the development of plant cultivars and their impact on agriculture. Crop Breeding and Applied Biotechnology, Viçosa, v.2, p. 47-56, 2012.

SUSAM. Secretaria de Saúde do Estado do Amazonas. Planos e Relatórios. 2019. Disponível em: http://www.saude.am.gov.br/servico/planos-relatorios. Acesso em 20 nov. 2019.

VASCONCELOS, M. A. M.; FARIAS NET0, J. T.; SILVA, F. C. F. Cultivo, processamento, padronização e comercialização do açaí na Amazônia. Fortaleza: Instituto Frutal, 2010. 113p.

VIEIRA, A. H.; RAMALH0, A. R.; ROSA NETO, C.; CARAR0, D. C.; COSTA, J. N. M.; VIEIRA JÚNIOR, J. R.; WADT, P. G. S. Cultivo do Açaizeiro (Euterpe oleracea Martius) no Noroeste do Brasil. Porto Velho: Embrapa Rondônia, 90 p, 2018. (Sistemas de produção, 36).

WADT, L. H. 0.; ONOFRA, C. R. A.; FERREIRA, E. J. L.; CARTAXO, C. B. C. Manejo de açai solteiro para produção de frutos. Rio Branco: Secretaria de Extrativismo e Produção Familiar, 2004. 34 p. (Documento Técnico, 02). 